\title{
THE ACTIVITY OF THE CARDIOREGULATORY AND ABDOMINAL SYMPATHETIC NERVES DURING SWALLOWING
}

\author{
Hiromasa OKada, Kyoko OKamoto AND Isamu Nisida* \\ Department of Physiology, Tottori University School of Medicine, Yonago
}

It has been stated that the swallowing acts are accompanied with changes of the respiratory $y^{9,14 \sim 16,18,19,22)}$ and gastrointestinal movements ${ }^{4,7.23)}$ as well as changes of the cardiovascular system. Concerning the changes of the circulatory system during deglutition some authors ${ }^{7,16,22,23)}$ have reported various effects, the bradycardia or tachycardia, and a fall or increase in the systemic blood pressure. However, the detailed behavior of the cardioacceleratory, cardioinhibitory and vasomotor centers during deglutition remains still obscure. Action potential study of the automic nerves innervating the heart and blood vessels is valuable in solving this problem.

The present study has been undertaken for the purpose of analysing such a problem by observing the efferent impulses in the sympathetic and parasympathetic nerves supplying the heart as well as the efferent impulses in the abdominal sympathetic nerves during reflex deglutition.

\section{METHODS}

As experimental animals, mainly cats and occasionally rabbits were used. The animals were lightly anesthetized with urethane $(0.25 \mathrm{~g} / \mathrm{kg}$.) and frequently decerebrated by means of the mid-collicular transection. Swallowing was elicited by pouring the water into the pharyngeal cavity through the tube by a syringe or by electrical stimulation of the central end of the severed superior laryngeal nerve. The nerve was stimulated with $1 \mathrm{msec}$. square wave pulses, $10-30 \mathrm{c} / \mathrm{sec}$, $0.5-5$ volts.

The superior or inferior cardiac sympathetic nerve and the cardiac branch of the vagal nerve were isolated from the surrounding tissues and cut beneath the heart after opening the chest by removing the first four ribs on the right or left side, the artificial ventilation being maintained ${ }^{6,20}$. The efferent impulses in the cardiac sympathetic nerve were mainly recorded on the left side, whereas those in the cardiac vagal nerve were led on the right side after removing the homolateral stellate ganglion. As indices of the vasomotor centers, the efferent impulses in the splanchnic nerve, hypogastric nerve and renal branch of the abdominal sympathetic nerve were used. These nerves were exposed retroperitoneally ${ }^{13}$ ) and divided into small nerve strands. In some cases, action potentials in the long ciliary nerve were recorded ${ }^{7}$ ). The efferent

Received for publication August 14, 1960

* 岡田博匡, 岡本恭子, 西田, 勇 
impulses in such autonomic nerves were led by means of the bipolar platinum electrode and amplified in a 'push-pull' arrangement and photographed with a magnetic oscillograph under visual control of a cathode-ray oscillograph. The contraction of the hyothyreoideal muscle was recorded on the oscillographic paper as a sign of the swallowing acts. In some instances the larynx and lower pharynx were removed and succinylcholine $(0.09-0.15 \mathrm{mg} / \mathrm{kg}$.) was intravenously administered. In such cases swallowing volleys in the proximal end of the external branch of the severed superior laryngeal nerve ${ }^{5}$ ) were used as an index of the swallowing.

\section{RESULTS}

I. The activity of the cardiac sympathetic nerve during swallowing; The efferent impulses in the cardiac sympathetic nerve of the cat showed a continuous activity as already found by numerous authors ${ }^{2,3,6,11,20,21)}$. When the water was poured into the pharyngeal cavity, the slightly increased activities in such action potentials were frequently provoked. Then they were completely inhibited for 0.85-0.95 sec., synchronizing with the appearance of deglutition. This inhibition usually occurred at the maximum of the contraction phase of hyothyreoideal muscle and continued longer than the end of the relaxation phase as shown in FIG. 1. In decerebrate cats a similar response described above was also recognized.

In other cases the central end of the severed superior laryngeal nerve in decerebrate cats was stimulated electrically, recording simultaneously the efferent impulses in the cardiac sympathetic nerve and in the external branch of the contralateral superior laryngeal nerve. The result was essentially similar to that obtained by the water-pouring. One example is shown in Fig. 2A. At the onset of the stimulation the activities of both nerves were firstly increased. Then the activity of the sympathetic nerve was completely suppressed for about 0.46-1.2 sec. at the onset of the swallowing volley in the superior laryngeal nerve. This inhibition usually lasted longer than the end of the swallowing volley and returned to the activity prior to inhibition. If the stimulation of the superior laryngeal nerve

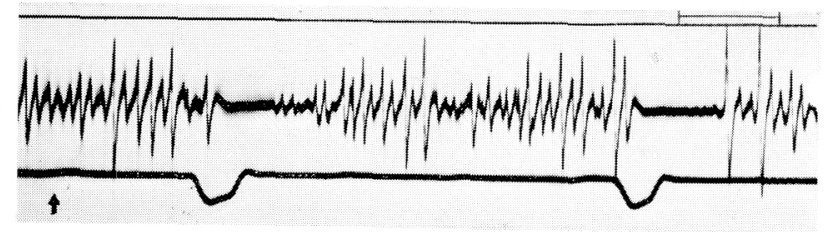

FIG. 1. Inhibition of the efferent impulses in the cardiac sympathetic nerve during swallowing.

Non-decerebrate cat $(2.2 \mathrm{~kg})$. Records from above downwards : efferent impulses in the left inferior cardiac sympathetic nerve, mechanogram of the hyothyreoideal muscle (downwards indicates contraction). Arrow indicates the beginning of the water-pouring. Time, $1 \mathrm{sec}$. 
was further continued, the inhibition of the activity in the sympathetic nerve was successively provoked in accordance with each swallowing volley. On cessation of the stimulation the activity of the superior laryngeal nerve was gradually decreased and lastly abolished, whereas the activity of the sympathetic nerve was instantaneously abolished or decreased for about 2 seconds and then returned to the original level (post-excitatory inhibition).

In the experiments on a few cats the intravenous administration of succinylcholine in addition to the severance of the bilateral glossopharyngeal, hypoglossal, superior laryngeal and cervical vagal nerves was performed for the purpose of ascertaining whether inhibition in the activity of the sympathetic nerve during deglutition was developed secondarily by afferent impulses which might be brought about by the contraction of the swallowing muscles and esophageal muscles. After such procedures the swallowing movements were no longer observed on the stimulation of the superior laryngeal nerve. However, electrical responses in the cardiac sympathetic nerve and superior laryngeal nerve were
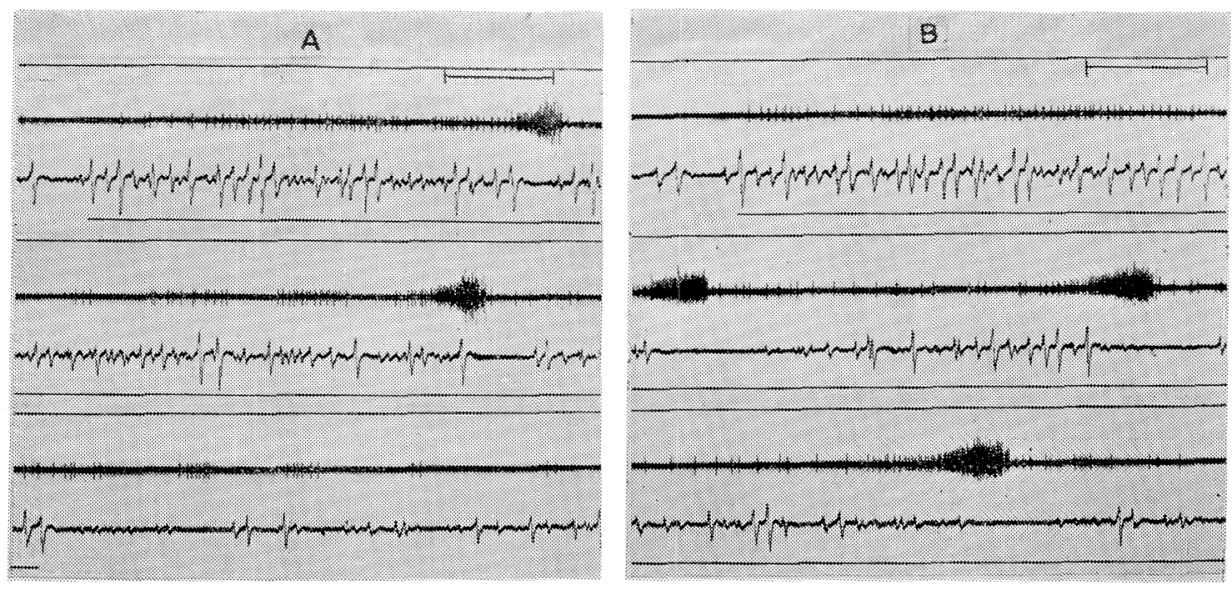

FIG. 2. Effect of the electrical stimulation of the central end of the severed superior laryngeal nerve upon the efferent impulses in the cardiac sympathetic nerve and the external branch of the superior laryngeal nerve.

Decerebrate cat $(2.2 \mathrm{~kg})$. Records A and B were obtained in the same cat.

A : after the severance of the IX, XII cranial nerves and bilateral superior laryngeal nerves, as well as, removing the larynx and lower pharynx.

B: 4 minutes after the intravenous administration of succinylcholine $(0.2 \mathrm{mg}$.) and additional severance of the bilateral cervical vagi.

Records from above downwards: the efferent impulses in the central end of the external branch of the left superior laryngeal nerve, the efferent impulses in the left inferior cardiac sympathetic nerve, the period of stimulation applied to the central end of the right superior laryngeal nerve. The stimulation frequency, duration and strength were $15 \mathrm{c} / \mathrm{sec} ., 1 \mathrm{msec}$. and 0.5 volts respectively. They were the same in both records. Time, $1 \mathrm{sec}$. 
similar to those before the administration of succinylcholine as shown in FIG. 2B.

From this result, it is assumed that inhibition of the activity in the cardiac sympathetic nerve during swallowing is not due to the afferent impulses elicited by the contraction of the swallowing muscles, but to a central connection between the cardiac sympathetic center and swallowing center.

II. The activity of the cardiac and thoracic vagal nerves during swallowing; In the cardiac branch of the vagal nerve of the cat the continuous efferent impulses could be found as already reported by the previous author ${ }^{20)}$. Efferent impulses from a single active unit obtained by dividing the nerve strand were recurred spontaneously at a relatively regular interval and 2.5-6 cycles per second in frequency. Such efferent impulses were also affected by the waterpouring into the pharyngeal cavity. One example is shown in Fig, 3. In this figure spontaneous activity being 2.7 cycles per second in frequency was instantaneously increased up to the frequency of $3.6 \mathrm{c} / \mathrm{sec}$. by the water-pouring. Then the activity was transitorily depressed in accordance with the appearance of a swallowing movement and soon it returned to the original level. Such reflex responses in the cardiac vagal nerve were eliminated by cutting the bilateral glossopharyngeal and superior laryngeal nerves. In decerebrate cats similar responses were also recognized.

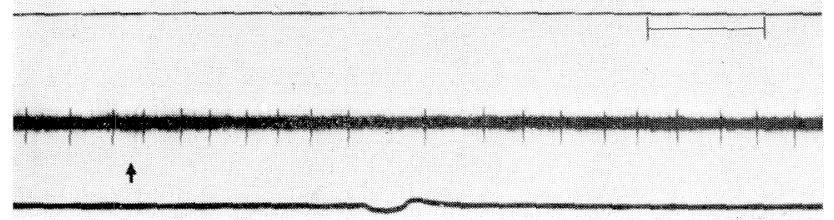

FIG. 3. The activity of the cardiac vagal nerve during deglutition.

Non-decerebrate cat $(4.0 \mathrm{~kg}$.). Records from above downwards : efferent impulses in a single activity unit of the right cardiac vagal nerve, mechanogram of the hyothyreoideal muscle (downwards indicates swallowing acts). Arrow indicates the beginning of the water-pouring. Time, 1 sec.

On the other hand, in spontaneous efferent impulses in the thoracic vagal nerve caudal to the region at which the cardiac vagal nerve branched from its trunk, the responses provoked by the water-pouring differed from those in the cardiac vagal nerve in some degree, i.e., the slightly increased activity was firstly produced by the water-pouring. Then it was followed by a vigorous activity lasting about 0.39 seconds, which was produced in accordance with each swallowing act (FIG. 4).

Such fibres in the thoracic vagal nerve seem to innervate the thoracic esophagus. However, from the reports of previous authors ${ }^{4,23}$ that swallowing acts were accompanied with the enhancement of the gastrointestinal movements, it is considered that some of such fibres may be innervating the gastrointestinal muscles. 


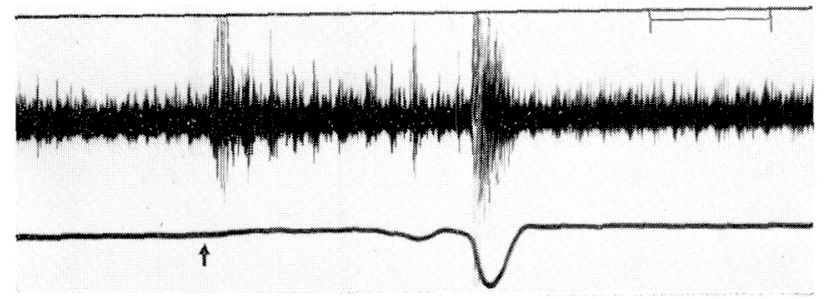

FIG. 4. The activity of the thoracic vagal nerve during deglutition.

Non-decerebrate cat $(4.2 \mathrm{~kg}$.). Records from above downwards : efferent impulses in the left thoracic vagal nerve, mechanogram of the hyothyreoideal muscle (downwards indicates swallowing acts). Arrow indicates the beginning of the water-pouring. Time, 1 sec.

III. The activity of the abdominal sympathetic nerve during swallowing; In the splanchnic nerve, hypogastric nerve and the renal branch of the abdominal sympathetic nerve in the cat, the continuous or pulse-synchronous efferent impulses were observed as already reported by previous authors $\mathrm{s}^{1,8,10,12,21}$. Effects of the water-pouring upon such efferent impulses were essentially similar in any abdominal sympathetic nerves. Fig. 5 shows the responses in the renal branch of the sympathetic nerve. When the water was poured into the pharyngeal cavity, the slightly enhanced activity in the nerve was frequently provoked. Such an effect was followed by a transitorily complete inhibition which occurred synchronously with each swallowing act and lasted about $0.93-1.43 \mathrm{sec}$. Then the activity returned to the resting level.

FIG. 6 shows the effect of the water-pouring upon the efferent impulses in the minor splanchnic nerve in the cat. In this figure the enhancement of the activity at the onset and during the water-pouring was considerably marked, whereas the inhibition of the activity during a swallowing act was slight. Such responses were abolished by cutting the bilateral glossopharyngeal and superior laryngeal nerves. In decerebrate cats similar results were also obtained.

In the rabbit the effects of the water-pouring upon the efferent impulses

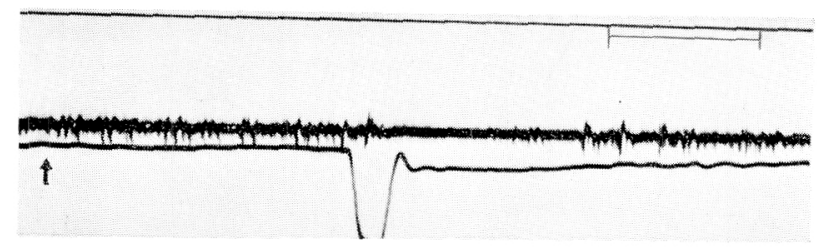

FIG. 5. The activity of the renal branch of the abdominal sympathetic nerve in the cat during swallowing.

Non-decerebrate cat $(3.0 \mathrm{~kg}$.). Records from above downwards : efferent impulses in a small nerve strand of the renal branch of the sympathetic nerve, mechanogram of the hyothyreoideal muscle (swallowing acts). Time, 1 sec. 


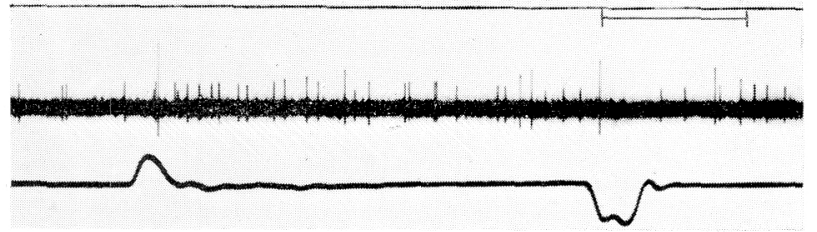

FIG. 6. The activity of the minor splanchnic nerve in the cat during swallowing.

Decerebrate cat $(1.8 \mathrm{~kg}$.). Records from above downwards: efferent impulses in a few active units of the minor splanchnic nerve, mechanogram of the hyothyreoideal muscle (upwards indicates the beginning of the waterpouring, downwards the contraction of the muscle). Time, $1 \mathrm{sec}$.

in the hypogastric nerve were similar to those in the abdominal sympathetic nerves in the cat. Inhibition in the rabbit during swallowing was however shorter in duration than that in the cat and lasted about 0.25-0.43 sec. Such inhibition could successively be provoked by the repeated water-pouring at short interval (FIG. 7A), although its degree showed a tendency of decrease after several times (FIG. 7B). After the cessation of the water-pouring for several minutes inhibition during the swallowing acts became again marked.

$I V$. Effects of deglutition upon the activity of the long ciliary nerve; In the long ciliary nerve of the cat the continuous efferent impulses could be detected as reported in the previous report ${ }^{1 \pi}$ ). However, such impulses were not affected on the swallowing movements elicited by the water-pouring.

$V$. Relation between the swallowing inhibition in the cardiac sympathetic nerve and the swallowing volley in the phrenic nerve; It was stated that there was

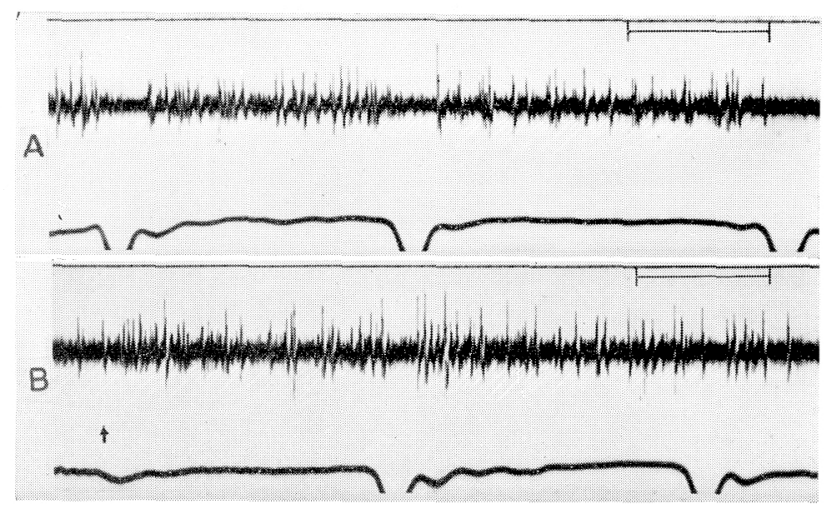

FIG. 7. The activity of the hypogastric nerve in the rabbit during swallowing.

Non-decerebrate rabbit $(1.8 \mathrm{~kg}$.). Records from above downwards: efferent impulses in a small nerve strand of the left hypogastric nerve, mechanogram of the hyothyreoideal muscle (downwards indicates the swallowing acts). Arrow indicates the water-pouring. A : effects of the first three deglutitions. B: effects of the 7 th and 8 th deglutitions. Time, 1 sec. 


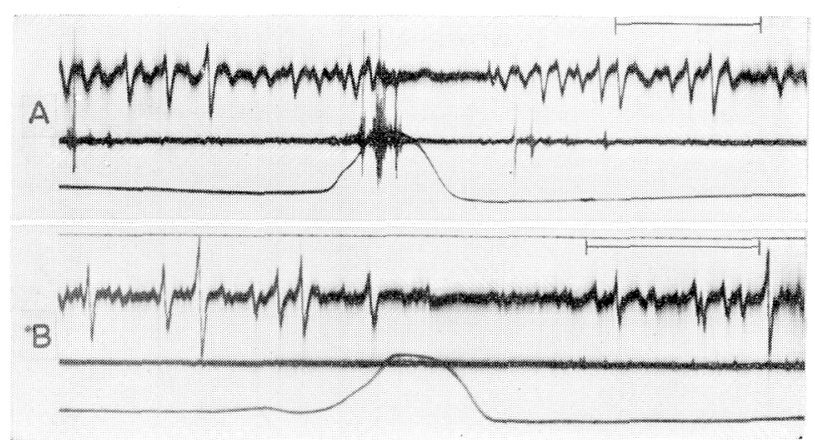

FIG. 8. Effects of artificial hyperventilation upon the swallowing volley in the phrenic nerve and swallowing inhibition of the activity of the cardiac sympathetic nerve.

Decerebrate cat $(2.5 \mathrm{~kg}$.). Open chest. A: about 30 seconds after the cessation of artificial hyperventilation. B: during stronger artificial hyperventilation. Records $\mathrm{A}$ and $\mathrm{B}$ were obtained in the same cat. Tracings from above downwards: efferent impulses in the left inferior cardiac sympathetic nerve, efferent impulses in the left phrenic nerve, mechanogram of the hyothyreoideal muscle (upwards indicates swallowing). Time, 1 sec.,

an intimate relation between the respiratory centers and the cardioregulatory or vasomotor centers, and that the swallowing acts were accompanied with a short respiration (swallowing respiration) which was elicited by impulses irradiating from the swallowing center to the respiratory centers $\left.{ }^{9,14} 16,18,19,22\right)$. Accordingly, a question arises whether the swallowing volley in the respiratory centers, which was induced by impulses irradiating from the swallowing center, has reference to the development of inhibition of the cardiac sympathetic center and vasomotor center or not. The following experiment was performed to decide this problem.

In action potentials from the phrenic nerve, discharging impulses rhythmically with the inspiratory phase, a short burst of swallowing volley occurred in accordance with deglutition as already reported in action potentials in the respiratory centers ${ }^{14)}$ or diaphragm ${ }^{19)}$. Such swallowing volley in the phrenic nerve as well as inhibition of the activity of the cardiac sympathetic nerve during deglutition could still be elicited under the depressed condition of the respiratory center brought about by artificial hyperventilation as shown in FIG. 8A. However, under the condition that the respiratory discharge was completely abolished by a stronger artificial hyperventilation, the swallowing volley in the phrenic nerve was no longer produced in spite of the appearance of the swallowing movements, whereas inhibition in the cardiac sympathetic nerve during deglutition could be elicited even under such conditions as illustrated in Fig. 8B.

This result suggests that the activity of the cardiac sympathetic centers may directly be inhibited by impulses irradiating from the swallowing center without mediation of the respiratory centers. 


\section{DISCUSSION}

From a series of experimental results described above, a diagram showing the behavior of the cardioacceleratory, cardioinhibitory and vasomotor centers during reflex swallowing is illustrated in FIG. 9.

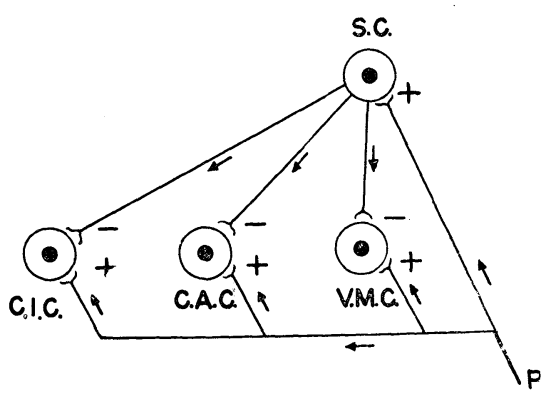

FIG. 9. Diagram showing the behavior of the cardioacceleratory, cardioinhibitory and vasomotor centers during reflex deglutition.

S.C.: swallowing center, C.I.C.: cardioinhibitory center, C.A.C.: cardioacceleratory center, V.M.C.: vasomotor center, P: afferent nerve from the pharyngeal wall, + : facilitatory effect, -: inhibitory effect.

The change of the activity of the cardioregulatory and vasomotor centers during swallowing seems to be attributed to the mechanism as follows: the afferent impulses, which are aroused by stimulation of the water-pouring, reach not only the swallowing center in the medulla oblongata but also the cardioacceleratory, cardioinhibitory and vasomotor centers, and they act facilitatorily upon such centers. Thus at the onset of the water-pouring the slightly enhanced activity in the cardiac sympathetic, cardiac vagal and abdominal sympathetic nerves is elicited. Such facilitatory effect is however overcome by inhibitory action of the abortive swallowing volley irradiating from the swallowing center to the cardioregulatory and vasomotor centers. Thus the slightly increased activity in the efferent nerves from such centers is followed by a transitorily complete or incomplete inhibition which occurs synchronously with the swallowing movements. Such inhibitory effect from the swallowing center seems to remain for a short time after the cessation of impulses irradiating from the swallowing center (inhibitory after-effect), because inhibition of the activity of the cardiac sympathetic and abdominal sympathetic nerves in the cat during swallowing lasts usually longer than the swallowing volley in the superior laryngeal nerve or the swallowing act (see Figs. 2, 5). However, in the rabbit such inhibitory after-effect may be less than that in the cat (see FIG. 7).

It is generally believed that the bradycardia or tachycardia during deglutition is due to variations in the vagal activity for the reason that they are abolished by cutting the vagi. On the other hand, the present results show that such changes in the heart rate may be brought about by variations of the activity in both the sympathetic and parasympathetic nerves to the heart.

The present study has demonstrated, furthermore, that the tonic activity of the splanchnic nerve, hypogastric nerve and renal branch of the sympathetic 
nerve, innervating the blood vessels of the splanchnic areas, firstly is increased by the water-pouring and subsequently is diminished or abolished synchronously with the occurrence of a swallow. It is assumed accordingly that in reflex swallowing the blood vessels of the splanchnic areas and kidney firstly constrict and then dilate. On the other hand, it has long been well known that the splanchnic nerve contains the nerve fibers innervating the gastrointestinal muscles besides vasoconstrictory fibers. Therefore, some of the fibers showing variations of the tonic activity during swallowing may be innervating the gastrointestinal muscles. This assumption may be supported by the work of SuMI ${ }^{23)}$ that the reflex inhibition of the intestinal movements is occasionally elicited by the water-pouring into the pharyngeal cavity after cutting the cervical vagi, and its effect is eliminated with the severance of the splanchnic nerves.

\section{SUMMARY}

The changes of the activity of the cardioregulatory and abdominal sympathetic nerves during reflex deglutition were investigated by means of action potential study.

1. The efferent impulses in the cardiac sympathetic nerve were slightly enhanced by pouring the water into the pharyngeal cavity. Then activity was completely inhibited with the occurrence of deglutition. Similar results were obtained by stimulating the central end of the severed superior laryngeal nerve. Such responses could still be evoked after the intravenous administration of succinylcholine.

2. The efferent impulses in the cardiac vagal nerve were slightly increased by the water-pouring. Then activity was transitorily suppressed with deglutition. 3. The tonic activity in the splanchnic nerve, hypogastric nerve and renal branch of the abdominal sympathetic nerves was slightly increased by the water-pouring. Then it was followed by a transitorily complete inhibition which occurred synchronously with each deglutition. Such responses were eliminated by cutting the bilateral glossopharyngeal and superior laryngeal nerves. On the other hand, the activity of the ocular sympathetic nerve was not affected by swallowing.

4. From the experimental results, a diagram showing the activity of the cardioregulatory and vasomotor centers during reflex swallowing was represented.

\section{REFERENCES}

1) Adrian, E. D., Bronk, D. W. and Phillips, G. J. Physiol. 74: 115, 1932.

2) Alexander, R. S. Amer. J. Physiol. 143: 698, 1945.

3) Alexander, R. S. J. Neurophysiol. 9: $205,1946$.

4) Anderson, B., Landgren, S., Neil, E. and Zotterman, Y. Acta physiol. scand. 20: 253,1950 . 
5) Andrew, B. L. J. Physiol. 134: 729, 1956.

6) Bronk, D. W., Ferguson, L. K., Margaria, R. and Solandt, D. Y. Amer. J. Physiol. 117: 237, 1936.

7) Comline, R. S. And Titchen, D. A. J. Physiol. 115: 210, 1951.

8) Dontas, A. S. Circulation Res. 3: 365, 1955.

9) Doty, R. S. Amer. J. Physiol. 166: 142, 1951.

10) Engelhorn, R. Arch. exp. Path. Pharmacol. 231: 219, 1957.

11) Fischer, T., Raule, R. und Seraphin, R. Pfü̈g. Arch. ges. Physiol. 262: 72, 1955.

12) Gernandt, B., Liljestrand, G. and Zotterman, Y. Acta physiol. scand. 11: 230, 1946.

13) Hukuhara, T. Pflüg. Arch. ges. Physiol. 238: 135, 1936.

14) Hukuhara, T. and Okada, H. Jap. J. Physiol. 6: 162, 1956.

15) MarckWald, M. Z. Biologie. 25: 1, 1889.

16) Meltzer, S. Arch. f. Anat. u. Physiol. Suppl.-Bd. 209, 1883.

17) Nisida, I.,Okada, H. and Nakano, O. Jap. J. Physiol. 10: 73, 1960.

18) Odanaka, T. J. Physiol. Soc. Jap. 14: 114, 1952 (Japanese).

19) Odanaka, T. J. Physiol. Soc. Jap. 14: 352, 1952 (Japanese).

20) Schaefer, H. Ergeb. Physiol. 46: 71, 1950.

21) Sell, R., Erdelyi, A. und Schaefer, H. Pflüg. Arch. ges. Physiol. 267: 566, 1958.

22) Steiner, Is. Arch. f. Anat. u. Physiol. Suppl.-Bd. 57, 1883.

23) Sumi, T. J. Physiol. Soc. Jap. 15: 601, 1953 (Japanese). 